\title{
Oh, esses gregos!
}

\section{Oswaldo Giacoia, Unicamp}

Resumo: Neste artigo apresento a crítica de Nietzsche à religião, moral e metafísica, a partir de uma perspectiva estética. As noções de graça e beleza são mobilizadas contra o peso e gravidade ascéticas, uma filosofia da corporalidade é pensada em antagonismo com o primado tradicional da razão e do intelecto. O artigo tematiza ainda o papel do humor e da ironia na crítica nietzscheana da metafísica.

Palavras-chave: Cultura; Metafísica; Estética

"Ademais, ele mesmo fez nascer de sua cabeça Atenea, de verdes olhos, terrível, belicosa, chefe de expedições, insaciável, venerável, a quem agradam os gritos, as guerras e as lutas."1

A esse registro mitológico do nascimento de Palas Atena a partir da cabeça de Zeus, podemos acrescentar também a legenda de Pandora, na qual Palas Atena ocupa um lugar de destaque, no que respeita ao destino dos homens:

Palas Atenea adaptou todo tipo de adornos a sua pele, e depois o mensageiro Argifonte teceu em seus peitos mentiras, palavras sedutoras e volúvel caráter, por vontade do ressonante Zeus; em seguida, o mensageiro dos deuses infundiu-lhe voz e chamou essa mulher de Pandora, porque todos os que habitam nas moradas olímpicas deram-lhe um dom: sofrimento para os homens, comedores de pão. ${ }^{2}$

Tais narrativas tornam possível um insight peculiar na autocompreensão da filosofia, comportando vários matizes: principio com a relação expressiva entre o nascimento da deusa e o lugar de sua proveniência: a cabeça é emblematicamente reconhecida como a sede do intelecto, o órgão da razão. Assim, a deusa da sabedoria nasce do intelecto de Zeus, e de nenhum útero; brota do crâneo, não da sexualidade, numa simbolização da concepção intelectual. A história de proveniência da filosofia, tal como a conhecemos a partir da tríade de seus ícones Sócrates, Platão e Aristóteles, reflete também, desde início, uma trajetória de denegação da sexualidade, especialmente a feminina, da inteira dimensão de seu corpo. A donzela Palas Atenea é a virgem sagrada, patrona da sabedoria, irmã gêmea do deus solar Apolo, assepticamente gerada do interior do crâneo de uma divindade superlativamente masculina.

Hesíodo referiu que Atenas foi quem adornou Pandora com um manto de prata e um maravilhoso véu bordado, pondo-lhe uma guirlanda de flores na cabeça, bem como uma coroa de ouro fabricada por Hefestos. Foi uma aliada de Zeus em sua luta contra os Titãs, e mais tarde contra os Gigantes, encarregando-se de buscar a ajuda de Hércules. Nascida inteiramentea adulta e já armada, Atena reivindicou a posse da cidade de Atenas plantando ali a primeira oliveira. Envolveu-se numa 
disputa com Poseidon pelo patronato da cidade, e Zeus designou como árbitros os olímpicos. Atenas foi sagrada vencedora porque a oliveira foi considerad a mais útil para os humanos; assumiu a tutela da cidade e emprestou-lhe o seu nome.

O princípio simbolizado por Atena é capaz de fundar cultura e civilização e manter a sociedade numa forma estável, integrada e organizada, pois é a deusa da sabedoria, da coesão social e da diplomacia, patrona das cidadelas, o núcleo vital das cidades, bem como mestra nas artes e ofícios manuais produtivos. Ela torna a guerra um instrumento social e político submetido ao intelecto, à disciplina e à ordem, antes do que um produto da pura barbárie e das paixões irracionais. Daí sua proximidade em relação a Apolo, seu irmão gêmeo e também ele deus da medida e da suprema sabedoria, manifestada pelo dístico no frontispício de seu oráculo em Delfos, que Sócrates transformou na insígnia da filosofia: conhece-te a ti mesmo.

Destaco todos esses elementos em vista de um propósito muito particular: o mito de Palas Atena expressa a relação ancestral entre a filosofia, como amor à sabedoria e uma atividade mental relacionada à essência mesma de Palas Atena: a teoria. Essencialmente ligada porque o verbo teorein significa contemplação, especulação, e com isso originariamente eidos atividade intelectiva, cerebral ligada à visão e à imagem, à luz solar na qual brilham os olímpicos Atena e seu irmão Apolo. Com isso, Palas Atena, enquanto imagem simbólica da sabedoria ilustra com plena nitidez uma experiência de mundo que discerne no sentido da visão, assim como no campo da imagem, a força motriz da intelectualidade e um poderoso fator na dinâmica do processo civilizatório.

Os próprios conceito de teoria e de contemplação estão, inclusive, etimologicamente vinculados a essa hegemonia do imagético e do visual. E nada dá testemunho mais vivo dessa pertença do que a alegoria da caverna de Platão, espécie de certidão de nascimento da metafísica ocidental. Para um acompanhamento desse mito de fundação, recorro à magistral interpretação de Martin Heidegger em Platons Lehre der Wahrheit.

O espaço físico mesmo da caverna é uma imagem simbólica do habitar humano no mundo, a figuração de um local de permanência, que se desvela para aquele que se dispõe a olhar em seu derredor. O mito da caverna é uma alegoria da Bildung, termo que evoca, ao mesmo tempo, formação e figuração. A caverna é a figura de um local, do âmbito de permanência de alguém que olha, um lugar no qual as coisas aparecem para aquele que as olha. O campo de visibilidade que esse olhar proporciona é descerrado pela luz do fogo, que ilumina essa estranha morada subterrânea. Imagem da profundidade, a caverna tem, inobstante essa dimensão, também um teto, uma abóboda.

Três imagens, três figuras de correspondência: entre a caverna e a morada, entre o fogo e a luz do Sol, entre a abóboda celeste e o teto da caverna. A situação dos prisioneiros colocados no interior da caverna é aquela própria de uma prisão: homens colocados sob a abóboda, com as cabeças voltadas para a terra. A caverna é uma figura (Bild) do mundo, da morada dos homens, e a filosofia não é outra coisa senão uma paidéia, uma formação sobretudo entendida como pedagogia do olhar.

Essa correção do olhar se perfaz nos movimentos descritos pela narrativa. Para os prisioneiros da caverna a imagem do mundo é aquela que se projeta contra o fundo da caverna, sob sua abóboda. Aquilo que assim se mostra é, por sua vez, cópia da cópia, uma sombra, um reflexo do real, tal como ele se mostra para alguém que olha. Na condição de homem atado a seus grilhões, a realidade que se apresenta é o 
que se mostra em seu horizonte de visibilidade, o âmbito deste mostrar-se é a dimensão do desvelamento, da verdade entendida como alétheia.

A caverna, assim como o mundo, é uma imagem e um sinal - um símbolo do lugar onde a verdade se mostra e se revela, verdade no sentido do que é representado e contemplado. No caso do prisioneiro da caverna platônica, nós sabemos que esse 'real' não passa de sombras projetadas, simulacros da realidade verdadeira. Verdade significa esse âmbito de exibição onde o ser ou o real apresenta-se como tal.

E aqui convém notar que o fogo, também ele, é imagem: a luz do fogo torna possível a projeção da sombra dos objetos, de modo que o fogo é o que permite ver, distinguir, vislumbrar. O fogo é, nesse sentido, tanto metáfora do sol (a fonte da luz), como também metáfora do olho (a fonte de luz do corpo). Quando um dos prisioneiros consegue libertar-se e voltar o pescoço, ele dá início à pedagogia do olhar: ele pode ver outras coisas além das sombras: os próprios objetos que são transportados defronte à abertura da caverna, bem como a luz do fogo que os ilumina; porque ele pode ver outras coisas, ele sabe também que a sombra tem origem nos objetos iluminados, sabe que o fogo é a condição de possibilidade de visão tanto dos próprios objetos quanto de suas sombras.

Libertar-se dos grilhões é a imagem da mudança da habitação, mas também da condição humana e do campo de visibilidade. Mexer a cabeça significa uma nova posição no mundo, que é o lugar onde as coisas (os entes) se manifestam. Mas essa nova condição, que permite distinguir entre as sombras e os objetos, é apenas um primeiro grau de libertação, pois o prisioneiro continua ainda no interior da caverna.

Mas essa não é uma experiência agradável, pelo contrário. Platão considera que o prisioneiro chega nela e por ela mais próximo do real, no sentido de inteirar-se mais daquilo que é revelado, desprovido de véu, afastado das sombras. Mas, com isso, a vista dói, pois o prisioneiro estava mais acostumado às sombras do que à luz, estava mais habituado à sombra do que o ao objeto que a produz.

Mas o prisioneiro evadido da caverna vê, então, as próprias coisas, e não suas imagens. Ele percebe, portanto, que as sombras projetadas no fundo da caverna eram imagens de imagens: eram sombras dos objetos que, por sua vez, eram apenas figurações: esculturas, por exemplo. Doravante, tendo se operado essa transformação em seu campo de visão, ele passa a ver as próprias coisas das quais as esculturas são representações ou imagens. O real não aparece mais como a cópia inanimada dos seres existentes, mas o real é constituído por esses seres mesmos, em sua efetividade e movimento. O fogo no interior da caverna e as imagens esculpidas são artefatos produzidos pelos homens, enquanto a realidade é formada por entes reais, não construídos pelos homens.

E, no entanto, de acordo com o jogo platônico de correspondências, também a realidade empírica dos entes existente tem a natureza da figura, da imagem: os próprios seres reais são Bild, uma figuração das essências ou de uma realidade superior a eles: as ideias, situadas no plano inteligível da abóboda celeste. Recorro aqui à interpretação de Heidegger que coloca acento especial na palavra Aussehen. Proponho traduzir essa palavra tanto por "aspecto" quanto por "feitio", "parecença", "figura". Algumas traduções francesas de Heidegger optam por évidence, para destacar a importância da figura e do olhar. Evidência é aquilo que se mostra, que salta aos olhos, aquilo que torna visível. As Ideias (eidos) significam para Platão a evidenciação do que as coisas (entes) são em seu ser. O 
verdadeiramente real é, para Platão, eidos, o ser dos entes, em sua totalidade, é ideia.

O fogo, dentro da caverna, é uma imagem do sol; o sol, fora da caverna, por sua vez, é uma imagem do Bem. O sol está para as coisas existentes assim como o fogo está para as esculturas, como a ideia do Bem está para as outras ideias. É a luz do fogo que permite que as sombras dos objetos esculpidos sejam percebidas como tais; é a luz do sol que permite ver a realidade empiricamente existente; é a ideia do Bem que dá Aussehen, visibilidade, por meio da luz da mente, a luz da alma, para as ideias, que são paradigmas ou protótipos das coisas existentes. A ideia do Bem é a ideia que torna alguma coisa apta a ser o que ela é, o que vale, portanto, para a realidade das próprias ideias. O desvelamento (alétheia) que permite discernir o ser das coisas em sua verdade passa a ser experimentado inteiramente no plano das ideias. Ideia é o nome da verdade do ser dos entes no momento de surgimento do pensamento como metafísica, e, com ela, da filosofia tal como a conhecemos no ocidente.

O prisioneiro liberto percebe agora que as próprias coisas são sombras, são figuras e imagens de entidades que, estas sim, são reais, não submetidas ao vir-a-ser e perecer: as coisas são cópias e imagens imperfeitas de entidades perfeitas - as ideias. O sol que ilumina a abóboda celeste, ele próprio, é uma imagem e uma metáfora: uma alegoria da ideia do Bem, a fonte e origem de todas as outras ideias. A pedagogia do olhar, que se inicia com um simples movimento de cabeça, culmina na contemplação das essências, no ideal do bios teoréticos, da vida contemplativa, própria da filosofia. A filosofia é abandono do mundo, preparação para a morte, para o retorno à pátria originária da alma, o mundo ideal inteligível, onde o olhar conquista a transparência absoluta, não turvada ou distorcida pela refração do corpo.

Aqui se revela também o estreito parentesco entre filosofia e ascese. A pedagogia do olhar encontra expressão na teoria da reminiscência. Conhecimento é essencialmente rememoração: a alma se recorda de um tempo em que habitou, livre o corpo, o mundo celeste das essências inteligíveis. É isso que incomoda tanto em pensadores como Arthur Schopenhauer e Friedrich Nietzsche.

A inserção deles na história da filosofia marca um acontecimento decisivo, uma nova forma de experiência filosófica do mundo: experiência que se pauta prima facie não mais pela via eidética do olhar, mas pela vivência tonal, não pela visão, mas fundamentalmente pela audição. Em seu espólio filosófico, encontramos uma anotação de Schopenhauer extremamente sugestiva a esse respeito:

uma explicação completa da música, em conceitos, seria uma explicação completa do mundo, em conceitos, portanto, seria a verdadeira filosofia... Toda música acompanhada de vozes é um análogo do mundo. Para mim, o baixo parece representar o inorgânico, sobre o qual tudo repousa e a partir do qual tudo se eleva: as vozes superiores, entretanto, são as organizações, ou seja, as espécies. ${ }^{3}$

Schopenhauer estima a música de modo tão elevado que, para ele, poderia não haver mundo, mas haveria a música. ${ }^{4}$

O leitor de $O$ Mundo poderia muito bem, em vez de dizer 'o mundo é fenômeno da vontade', na verdade afirmar 'o mundo é fenômeno da Música'. O próprio título do opus magnum de Schopenhauer, em vez de $O$ Mundo como Vontade e como 
Representação, poderia ser $O$ Mundo como Música e como Representação. Surpreendente: "Schopenhauer não só torna a coisa-em-si kantiana cognoscível, como a fez cantar!" 5

Para Schopenhauer,

apenas que em cada uma delas de uma maneira completamente diferente, então não pode haver, de modo algum, nenhuma semelhança imediata entre elas, mas por certo a música não é, de modo algum, como as outras artes, um reflexo das ideias, mas um reflexo da própria vontade, da qual as ideias são também uma objetidade: justamente por causa disso o efeito da música é tão mais poderoso e penetrante do que o das outras artes: pois estas falam apenas de sombras, a música, porém, fala da essência. Uma vez que é a mesma vontade que se objetiva tanto nas ideias como na música, um paralelismo, uma analogia entre a música e as ideias, cuja manifestação é o mundo visível em sua multiplicidade e imperfeição. ${ }^{6}$

Se Schopenhauer reconhece no 'divino Platão' uma das pilastras de sua própria filosofia, no caso de Nietzsche, sua concepção de filosofia sempre se realizou como uma tentativa deliberada de inversão (Umwertung) da metafísica de Platão, e do idealismo que a ela se vincula. Para Nietzsche, sem música o mundo seria um erro:

O verdadeiro mundo é música. A música é o Inaudito. Quando a ouvimos, pertencemos ao ser. Assim Nietzsche a vivenciava. Era tudo para ele. Não deveria cessar nunca. Mas ela cessa, e por isso temos o problema de como continuar vivendo quando a música acaba. ${ }^{7}$

A despeito dessa divergência quanto à relação com Platão, temos em Schopenhauer e Nietzsche uma experiência de mundo que não privilegia o intelecto, mas a vontade, não a razão, mas as pulsões, não a consciência e o ego, mas o inconsciente e o corpo. Talvez seja por essa razão que a ambos é imputado com tanta rapidez e incompreensão o epíteto de irracionalista. Trata-se, a meu ver, de uma leviandade, pois esse irracionalismo é epidérmico; nas entranhas encontra-se um conceito ampliado de razão, a grande razão do corpo. Esta celebra suas saturnais da experiência artística musical.

Para Nietzsche, o próprio universo dos afetos, a que a canção lírica tem acesso, só pode ser interpretado a partir de um estado cuja natureza é essencialmente musical. Por meio do mundo simbólico dos afetos, o lírico interpreta para si a música, enquanto ele mesmo, no repouso da intuição apolínia, está descarregado daqueles afetos. Quando, pois, o músico compõe uma canção lírica, ele, como músico, não é estimulado nem pelas figuras nem pela linguagem de sentimentos desse texto, porém uma excitação musical vinda de esferas inteiramente outras escolhe para si aquele texto da canção, como uma expressão alegórica de si mesma. Portanto, não se pode falar de uma relação necessária entre canção e música; pois os dois mundos aqui postos em relação, do som e da figura, encontram-se demasiado distantes para poder contrair uma ligação mais do que exterior:

A canção é precisamente apenas símbolo e se comporta para com a música como o hieróglifo egípcio da coragem para com o próprio guerreiro corajoso. Nas supremas revelações da música, sentimos involuntariamente 
a rudeza de toda figuratividade e de todo efeito trazido por analogia: como, por exemplo, os últimos quartetos de Beethoven envergonham completamente toda intuitividade, em geral o inteiro reino da realidade empírica. Em face do deus supremo manifestando-se efetivamente, o símbolo não tem mais nenhum significado: sim, ele agora aparece como uma ofensiva exterioridade. ${ }^{8}$

A relação entre a música e a poesia é a mesma que se pode apreender, na linguagem, entre a palavra como portadora da semântica, conceitualmente apreensível, e o subsolo tonal da própria língua: o tom ou musicalidade da inflexão, essa autêntica quintessência do mundo. Por isso, de acordo com seu biógrafo autorizado, um filósofo musicalmente susceptível, como Schopenhauer, pode duvidar da vocação autenticamente musical do gênio wagneriano. Ao receber, por intermédio de amigos comuns, uma partitura do Anel do Niebelungo, Schopenhauer, antes de Nietzsche, já imputava a Richard Wagner certa degradação da autonomia da música.

"Transmita ao vosso amigo", aconselha ele ao intermediário, "o meu obrigado pelo envio do seu 'Niebelungo', mas que ele renuncie à música, já que tem muito mais gênio para a poesia! Eu, Schopenhauer, continuo fiel a Rossini e a Mozart. ${ }^{9}$

Nessa relação abre-se uma possibilidade de captar uma nova teoria da potência expressiva da sonoridade e da música, que, em Nietzsche, conduz à experiência propriamente linguística para o domínio do pré-linguiístico, do não linguístico, onde a expressão - e as possibilidades de compreensão - podem vislumbrar-se em aspectos do falar não são transponíveis em palavras-conceitos.

Nietzsche tratou desse problema sob outro título, isso é, em suas relações estético-musicais que, todavia, são também de eminente interesse hermenêutico, pois que nelas, decerto, é defendida a tese de que é pensável uma compreensão da essência das coisas e, com efeito, no médium da música, como da mais pura conformação do fenômeno do tom. Por conseguinte, as discussões filosófico-linguísticas desembocam organicamente na explicação da linguagem em sua 'forma mais originária', isto é, como puro acontecimento tonal. ${ }^{10}$

Percebemos, pois, que também o jovem Nietzsche, como seu mestre Arthur Schopenhauer, considera possível uma compreensão (musical) da essência do mundo. Os limites subjetivos necessariamente impostos ao conhecimento dos objetos empíricos ficariam superados numa experiência do mundo autenticamente musical: a vivência acústica, tal como pode ser realizada na composição e na audição musical, pode superar as limitações do conhecimento meramente individual, aquelas fronteiras da representação submetida ao princípio de individuação e à quádrupla raiz do princípio de razão suficiente.

Não deveríamos chegar aqui ao discernimento do que é o poeta lírico, isto é, o homem artístico que tem de interpretar para si a música por meio da simbólica das figuras e afetos, que nada tem, contudo, a comunicar ao 
ouvinte: que, em pleno enlevo, até mesmo esquece quem se coloca avidamente à escuta em sua proximidade? E como o poeta lírico canta seu hino, do mesmo modo canta o povo a canção popular, para si, por um ímpeto interior, indiferente se a palavra é compreensível para quem não canta junto. Pensemos em nossas próprias experiências no domínio da arte musical superior: o que compreendemos do texto de uma missa de Palestrina, de uma cantata de Bach, de um oratório de Händel, se nós mesmos não cantamos junto? Somente para aquele que canta junto há uma lírica, há uma música popular. ${ }^{11}$

Se existe uma unio mystica em Arthur Schopenhauer, préfigurada intuitivamente no misterioso sentimento de compaixão, mas efetivamente realizada nas figuras autocontraditórias da santidade e da ascese, como superação definitiva da individualidade, é porque nela as dores do mundo se identificam com a dor própria, rasgando o véu de Maya da ilusão egoica. Ora, assim também existe, no antípoda absoluto da ascese - a saber, na celebração nietzscheana da embriaguez e do delírio - um correspondente místico dessa fusão com o absoluto: o Rausch dionisíaco, paroxisticamente vivido nas bacanais, como santificação da sexualidade como eterno caminho da vida plena, não é uma embriaguez etílica ou produzida por qualquer forma de entorpecente; mas a penetração (necessariamente induzida pelo espírito da música) no fluxo incessante do vir-a-ser, com seus movimentos de prazer e dor, criação e destruição, agonia e êxtase.

Por essa razão, penso que só podemos compreender plenamente a filosofia como experiência do mundo em Schopenhauer e em Nietzsche, se formos suficientemente sensíveis para interpretá-la num registro essencialmente musical. O pensamento de ambos dá origem a uma filosofia do trágico, que se abisma no caráter absurdo do existir, para o qual vale a sabedoria mortal de Sileno, bem como o lamento de Calderón de la Barca, ecoado por Schopenhauer: a vida é o que não deve ser, pois o delito maior é ter nascido. Nesses dois pensadores - no filósofo da compaixão, e no pensador da crueldade do existir - a música é, de fato, antecâmara do absoluto, na qual se penetra seja para celebrá-lo no êxtase dionisíaco, ou para renegá-lo na experiência do Nirvana.

O universo da experiência musical é verdadeiramente fundamental, porque a música transporta para o plano da vivência profunda, pré-linguística e pré-verbal, o que é o mais íntimo e essencial do mundo pensado como vontade: as sensações inarticuladas de prazer e de dor. Penetrar no átrio do santuário musical significa transitar do plano representacional, verbal, linguístico, figurativo, da palavra e do sentimento articulado, para o universo sem limites de sua origem sagrada: o Uno Primordial, em Nietzsche, ou a essência metafísica do universo, eternamente sofredora, em Schopenhauer. Só a música opera essa intimidade e transição prélinguística, no médium do som: o fundamento sem fundo.

Sabemos que, para Nietzsche, a verdade é mulher; e como os filósofos sempre foram canhestros e desajeitados com as mulheres, eles jamais foram capazes de conquistar essa potência feminina da verdade. Eis aqui a inversão mais radical possível da narrativa mítica do nascimento da deusa da sabedoria a partir da cabeça de Zeus. Nesse sentido, o filósofo escreve, em provocação afrontosa de seus pares filosóficos: 
Não, esse mau gosto, essa vontade de 'verdade a todo custo', esse desvario adolescente no amor à verdade - nos aborrece: para isso somos demasidadamente experimentados, sérios, alegres, escaldados, profundos... Já não cremos que a verdade continue verdade, quando se lhe tira o véu... Hoje é, para nós, uma questão de decoro não querer ver tudo nu, estar presente a tudo, compreender e 'saber tudo'. 'É verdade que Deus está em toda parte?', pergunta uma garotinha à sua mãe; 'não acho isso decente' um sinal para filósofos!... Devíamos respeitar mais o pudor com que a natureza se escondeu por detrás de enigmas e de coloridas incertezas. Talvez a verdade seja uma mulher que tem razões pra não deixar ver suas razões? Talvez o seu nome, para falar grego, seja Baubo?... Oh, esses gregos! Eles entendiam do viver! ${ }^{12}$

Perceba-se bem, talvez o nome da verdade seja Baubo, e não Palas Atena. Baubo, a antiga Deusa Grega do Ventre, conhecida também pelo nome de Lamba. Baubo esposa de Dysaules e mãe de Mise. Em suas representações não possui cabeça, e sim um rosto que aparece no torso.

Sua história nos chega da Antiga Grécia, quando Deméter era a Deusa Mãe da Terra e todos os dias passeava pelos prados para cuidá-los, garantindo assim que houvesse abundância no planeta. Regava as plantas, fazia florescer as árvores, sempre acompanhada da filha Perséfone que amava profundamente. Certo dia, Hades, o Deus dos Infernos sequestrou Perséfone e a levou para as entranhas da terra. Deméter caiu então, em profunda depressão. A terra reflete seu desespero e os campos se tornam estéreis. Deméter em sua peregrinação atrás da filha chega a um lugar chamado Eleusis chorando muito.

Baubo, vendo-a tão desesperada, acerca-se de Deméter dançando, levanta a saia e mostra-lhe a vulva. Deméter sorriu, Baubo abraçou-a e disse-lhe que, como Deusa da Terra, ela não poderia ser destruidora e sim transformadora. Em seguida continuou contando-lhe histórias bem picantes e engraçadas, que faziam as duas rir muito, até que a Mãe da Terra adquiriu novas forças para ir à busca da filha. A Terra riu com as Deusas, e a partir de então a terra floresceu. 


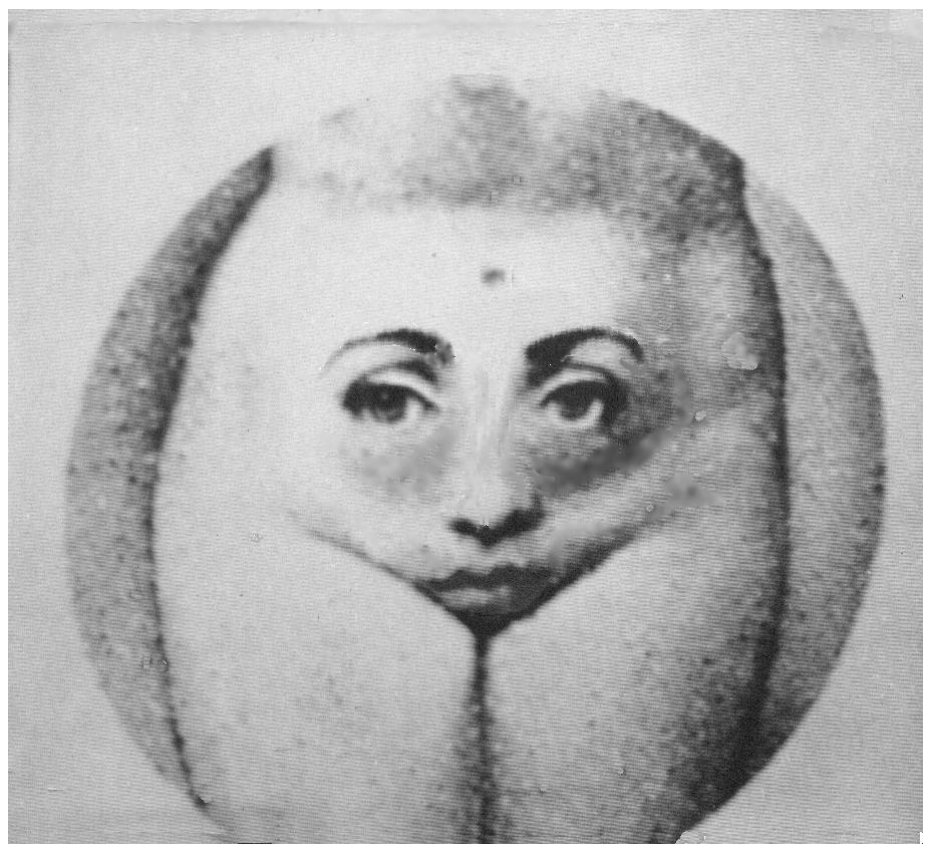

A dimensão contagiante da alegria e do riso sagrado, junto com as festividades e cerimoniais em que se vê envolto, afasta a humanidade de seus pesares que constantemente os aferroam, afirma a vida e vence os temores da morte e da esterilidade. Baubo é, assim, num dos livros mais pronunciadamente antiplatônicos de Nietzsche, a cifra da imortalidade por meio do caminho bendito da sexualidade, da dança e do riso; e a filosofia, celebrando sua reconciliação dionisíaca com a natureza, se libera de sua aliança com os ideais ascéticos e com a negação niilista da existência.

Através da alegria e do riso, da música e da dança (Baubo é uma personagem mítica de A Gaia Ciência) nos esquecemos dos limites de nossa existência, além de nos ajudar a vencer obstáculos que põem em perigo a continuidade da vida. A música e o riso são um bálsamo para as feridas da existência. Trata-se de uma fusão com o caudal da vida eterna, numa experiência que nos é descerrada por uma profunda vivência musical.

\begin{abstract}
In this article I present Nietzsches criticism on religion, morality and metaphysics, from an aesthetic perspective. The notions of grace and beauty are mobilized against the weight and ascetic severity, a philosophy of corporeality is thought antagonistically to the traditional primacy of reason and intellect. The article also thematizes the role humor and irony in Nietzsche's critique of metaphysics.
\end{abstract}

Keywords: Culture; Metaphysics; Aesthetics. 


\title{
Referências:
}

BARBOSA, J. L. A Metafísica do Belo de Arthur Schopenhauer. São Paulo: Humanitas, 2001

FIGL, J. Die Dialektik der Gewalt. Düsseldorf: Patmos, 1984.

HEIDEGGER, Martin. Platons Lehre von der Wahrheit. $4^{\mathrm{a}}$ ed. Frankfurt: Klostermann, 1997.

HESÍODO. Teogonia, 925. In: Teogonia. Trabalhos y Dias. Escudo. Certamen. Trad. Adelaida y María Angeles Martin Sánchez. Madrid: Alianza Editorial, 1986.

NIETZSCHE, F. Sämtliche Werke. Kritische Studienausgabe (KSA). Ed. G. Colli und M. Montinari. Berlin, New York, München: de Gruyter, DTV. 1980.

NIETZSCHE, F. A Gaia Ciência. Prólogo, nr. 4. Trad. Paulo César de Souza. São Paulo: Companhia das Letras, 2001.

SAFRANSKI, R. Nietzsche. Biografia de uma Tragédia. Trad. Lya Luft. São Paulo: Geração Editoria, 2001.

SCHOPENHAUER, A. Die Welt alsWille und Vorstellung I. Parágrafo 52 do LivroTerceiro. In: Werke. Ed. Wolfgang Frhr. Von Löhneysen.Frankfurt/M: Suhrkamp, 1986. Safranski, R. Nietzsche. Biografia de uma Tragédia. Trad. Lya Luft. São Paulo: Geração Editoria, 2001.

\begin{abstract}
In this article I present Nietzsches criticism on religion, morality and metaphysics, from an aesthetic perspective. The notions of grace and beauty are mobilized against the weight and ascetic severity, a philosophy of corporeality is thought antagonistically to the traditional primacy of reason and intellect. The article also thematizes the role humor and irony in Nietzsche's critique of metaphysics.
\end{abstract}

\section{Referências}

BARBOSA, J. L. A Metafísica do Belo de Arthur Schopenhauer. São Paulo: Humanitas, 2001

Figl, J. Die Dialektik der Gewalt. Düsseldorg: Patmos, 1984.

HESÍODO. Teogonia, 925. In: Teogonia. Trabalhos y Dias. Escudo. Certamen. Trad. Adelaida y María Angeles Martin Sánchez. Madrid: Alianza Editorial, 1986.

NIETZSCHE, F. Sämtliche Werke. Kritische Studienausgabe (KSA). Ed. G. Colli und M. Montinari. Berlin, New York, München: de Gruyter, DTV. 1980.

NIETZSCHE, F. A Gaia Ciência. Prólogo, nr. 4. Trad. Paulo César de Souza. São Paulo: Companhia das Letras, 2001. 
SAFRANSKI, R. Nietzsche. Biografia de uma Tragédia. Trad. Lya Luft. São Paulo: Geração Editoria, 2001.

SCHOPENHAUER, A. Die Welt alsWille und Vorstellung I. Parágrafo 52 do LivroTerceiro. In: Werke. Ed. Wolfgang Frhr. Von Löhneysen.Frankfurt/M: Suhrkamp, 1986. Safranski, R. Nietzsche. Biografia de uma Tragédia. Trad. Lya Luft. São Paulo: Geração Editoria, 2001.

\section{Notas}

${ }^{1}$ Hesíodo. Teogonia, 925. In: Teogonia. Trabalhos y Dias. Escudo. Certamen. Trad. Adelaida y María Angeles Martin Sánchez. Madrid: Alianza Editorial, 1986, p. 54.

${ }^{2}$ Hesíodo. Trabajos y Dias, 70-80. Teogonia. In: Teogonia, Trabalhos y dias. Escudo. Certamen. Trad. Adelaida y María Angeles Martin Sánchez. Madrid: Alianza Editorial, 1986, p. 71. Na nota 18 dessa edição, lemos: "Pandora originariamente fue um epíteto de la madre tierra 'dadora de todo', y aparece representada em vários vasos saliendo de la tierra. Después fue considerada mensajera de la tierra y, como la tierra, protótipo de la mujer. Cf. Pausanías, I, 24, 7.” Cf. op. cit., p. 96.

3 Apud Barbosa, J. L. A Metafísica do Belo de Arthur Schopenhauer. São Paulo: Humanitas, 2001, p.131s.

${ }^{4}$ Cf. Schopenhauer, A. Die Welt als Wille und Vorstellung I. Parágrafo 52 do Livro Terceiro. In: Werke. Ed. Wolfgang Frhr. Von Löhneysen. Frankfurt/M: Suhrkamp, 1986, Vol. I, p. 359s.

${ }^{5}$ Barbosa, J. L. A Metafísica do Belo de Arthur Schopenhauer. São Paulo: Humanitas, 2001, p.131.

${ }^{6}$ Schopenhauer, A. Die Welt als Wille und Vorstellung I. Parágrafo 52 do Livro Terceiro. In: Werke. Ed. Wolfgang Frhr. Von Löhneysen. Frankfurt/M: Suhrkamp, 1986, Band I, p. 359s.

7 Safranski, R. Nietzsche. Biografia de uma Tragédia. Trad. Lya Luft. São Paulo: Geração Editoria, 2001, p. 13.

${ }^{8}$ Nietzsche, F. Fragamento inédito da primavera de 1871, numerado como 12 [1]. In: Sämtliche Werke. Kritische Studienausgabe (KSA). Ed. G. Colli und M. Montinari. Berlin, New York, München: de Gruyter, DTV. Band 7, p. 359s. Tradução brasileira publicada em Discurso. Revista do Departamento de Filosofia da USP. Nr. 37, 2007. Trad. Oswaldo Giacoia Junior, p. 167-182. A passagem citada encontra-se na p. 177.

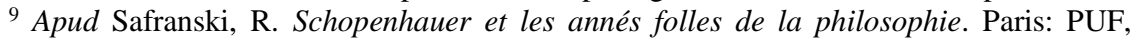
1990, p. 433.

${ }^{10}$ Figl, J. Die Dialektik der Gewalt. Düsseldorf: Patmos, 1984, p. 154.

${ }^{11}$ Nietzsche, F. Fragmento inédito da primavera de 1871, numerado como 12 [1]. In: Sämtliche Werke. Kritische studienausgabe (KSA). Ed. G. Colli und M. Montinari. Berlin, New York, München: de Gruyter, DTV. Band 7, p. 359s. Tradução brasileira publicada em Discurso. Revista do Departamento de Filosofia da USP. Nr. 37, 2007. Trad. Oswaldo Giacoia Junior, p. 167-182. A passagem citada encontra-se na p. 181.

${ }^{12}$ Nietzsche, F. A Gaia Ciência. Prólogo, nr. 4. Trad. Paulo César de Souza. São Paulo: Companhia das Letras, 2001, p. 14s. 